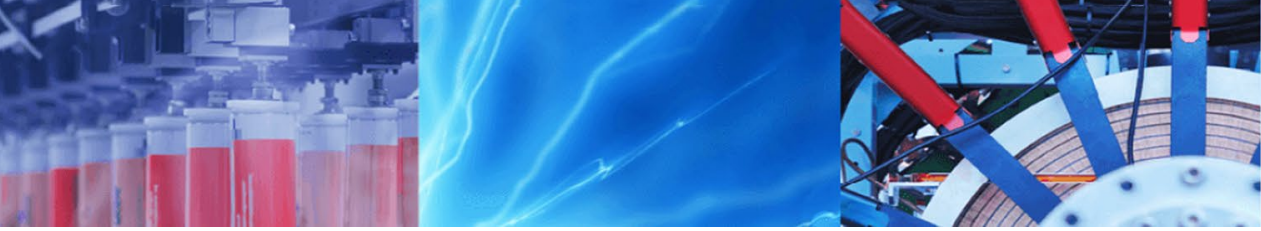

Research Article

\title{
Taguchi grey relational analysis for parametric optimization of severe plastic deformation process
}

\author{
B. M. Girish ${ }^{1}$ (1) H. S. Siddesh ${ }^{2} \cdot$ B. M. Satish
}

(c) Springer Nature Switzerland AG 2019

\begin{abstract}
In this paper, a new effective approach, Taguchi grey relational analysis has been applied to experimental results in order to optimize the severe plastic deformation process parameters with consideration to multiple performance measures. The approach combines the orthogonal array design of $L 27$ experiments with grey relational analysis. Grey relational analysis is adopted to determine the best process parameters that give ultrafine grain structure leading to enhanced mechanical properties. The response table and the grey relational grade for each level of the process parameters has been established. The parameters that were considered were the specimen thickness of $3 \mathrm{~mm}, 4 \mathrm{~mm}$ and $5 \mathrm{~mm}$; the displacement rates of $1.0 \mathrm{~mm} / \mathrm{min}, 1.5 \mathrm{~mm} / \mathrm{min}$ and $2.0 \mathrm{~mm} / \mathrm{min}$; and the number of passes which were 1,3 and 5 . A total of 27 experiments were conducted. The optimum parameter values producing the highest value of grey relational grade was allotted rank one which pertained to the factors setup for experiment number 17 having $1.5 \mathrm{~mm} / \mathrm{min}$ as the displacement rate, with 5 numbers of pass and thickness of specimen being $4 \mathrm{~mm}$.
\end{abstract}

Keywords Al $6061 \cdot$ SPD process · Mechanical properties · Optimization · Grey relational analysis

\section{Introduction}

The process of severe plastic deformation (SPD) is gaining great interest in the field of material science and engineering in view of its usefulness in refining the microstructure to nanometer levels. In Al-based alloys, it is generally difficult to reduce the grain size below $10 \mu \mathrm{m}$ through the conventional recrystallization process following thermos-mechanical treatments. This difficulty arises from the inherent nature of Al alloys that the stacking fault energy is relatively large so that it is easy for the recovery of dislocation to occur. One of the advantages is the capability of producing large samples that are free from any residual porosity and readily amenable to mechanical testing and forming operations. In terms of using severe plastic deformation to produce nanostructure sheets [1-3], two major severe plastic deformation techniques, which are mostly employed, are accumulative roll bonding [4] and constrained groove pressing [5]. The constrained groove pressing process, introduced by Shin et al. [6], involves repetitive corrugating and flattening stages. During constrained groove pressing, the work piece is subjected to cyclic shear deformation by utilizing asymmetrically grooved dies and flat dies. In this technique, the gap between the upper die and lower die is identical to the sample thickness and therefore the inclined part of the sample, located in the groove, is subjected to pure shear deformation [7]. By imposing more constrained groove pressing passes, higher strains are introduced to the work piece. The work piece subjected to severe plastic deformation by applying three passes of constrained groove pressing resulted in a total strain of 3.48. This led to ultrafine grain low carbon steel having the grains of $260-270 \mathrm{~nm}$. Recently, many

$\triangle$ B. M. Girish, bmgiri1@gmail.com; H. S. Siddesh, skphss@gmail.com; B. M. Satish, satishbhujangmutt@gmail.com |'Department of Mechanical Engineering, Alliance College of Engineering and Design, Alliance University, Bangalore 562106, India. ${ }^{2}$ Department of Mechanical Engineering, ACS College of Engineering, Bangalore 560074, India. ${ }^{3}$ Department of Mechanical Engineering, APS College of Engineering, Bangalore 560082, India.

SN Applied Sciences (2019) 1:937| https://doi.org/10.1007/s42452-019-0982-6

Received: 25 May 2019 / Accepted: 24 July 2019 / Published online: 30 July 2019 
works are carried out to study the mechanical properties and microstructural evolutions of different materials such as low carbon steel, aluminium and copper alloys subjected to constrained groove pressing. According to these studies [8-12], the constrained groove pressing process can effectively enhance the mechanical properties of sheet metals.

The material used in the present study was aluminium alloy (Al) 6061. It contains magnesium and silicon as its major alloying elements. The chemical composition of the alloy is presented in Table 1. Al 6061 has good mechanical properties, exhibits good weldability and can be conveniently extruded, forged, or rolled to a variety of shapes and sizes. It can be easily brazed and has very good corrosion resistance, good machinability and workability. It is a medium to high strength alloy which is widely used in aircraft structures such as fuselages and wings.

It is important to develop an optimal manufacturing method in severe plastic deformation process. The advantage of grey multiple attributes decision is that it has been clearly observed that the number of passes (B) has the highest amount of contribution and the displacement rate (A) has the second highest contribution on the response values. The specimen thickness $(C)$ and interaction factors show a very less amount of contribution. The results in terms of the change in mechanical properties are discussed.

The objectives of the research paper is to establish a relationship between the various process parameter like displacement rate, thickness of the plate and number of passes and the microstructure of the specimen obtained and the effect of the process parameters on the mechanical properties of Al 6061 alloy. The results in terms of micro structural characteristics and the change in mechanical properties are discussed in this paper.

\section{Design of experiments}

The design of experiments (DOE) approach using Taguchi technique has been successfully applied by several researchers in various studies relating to aluminum-based alloys and composites. Taguchi technique significantly reduces the number of experiments that are required to model the response function compared to the full factorial design of experiments. A major advantage of this technique is to find the possible interaction between the various parameters [13, 14]. Design of experiments is one of the many problem-solving quality tools that can be used for various investigations such as finding the significant factors in a process, the effect of each factor on the outcome, the variance in the process, troubleshooting the machine problems, screening the parameters, and modeling the processes. Many industries use this tool to stay competitive worldwide by designing robust products as well as improving quality and reliability of a product. By using strategically designed and statistically performed experiments, it is possible to study the effect of several variables at one time, and to study inter-relationships and interactions $[15,16]$.

In the present study, the parameters considered in the experiments are the displacement rate, thickness of the test specimen, and the number of passes for various compressive displacement rates in order to study the grain refinement and its effect on mechanical properties. Taguchi Orthogonal Array (OA) was employed to develop the experimental layout. Table 2 shows the three parameters and their levels considered in the experiment.

\subsection{Taguchi orthogonal array (OA) design}

A matrix experiment consists of a set of experiments where the settings of the various product or process parameters in consideration are changed from one experiment to another. After conducting a matrix experiment, the data from all the experiments in the set are taken together and analyzed to determine the effects of the various parameters. Conducting matrix experiments using special matrices, called orthogonal arrays, allows the effects of several parameters to be determined efficiently.

Taguchi orthogonal array designs are repeatedly used in design experiments with multiple level factors. Taguchi orthogonal array can be thought of as a general fractional factorial design process. However, before constructing an orthogonal array, the following requirements must be defined.

1. Number of factors to be studied: In the present study the numbers of factors to be studied are 3. They are strain rate of specimen compression in $\mathrm{mm} / \mathrm{min}$, number of passes assigned for compression, and the thickness of the test specimen in $\mathrm{mm}$.

Table 2 Experimental parameters and their levels

\begin{tabular}{llllll}
\hline Factor & Name & Unit & \multicolumn{3}{l}{ Levels } \\
\hline A & Displacement rate & $\mathrm{mm} / \mathrm{min}$ & 1 & 1.5 & 2 \\
B & Number of pass & - & 1 & 3 & 5 \\
C & Thickness & $\mathrm{mm}$ & 3 & 4 & 5 \\
\hline
\end{tabular}

Table 1 Chemical composition of Al 6061 alloy in wt\%

SN Applied Sciences

a SPRINGER NATURE journal

\begin{tabular}{llllllll}
\hline $\mathrm{Mg}$ & $\mathrm{Si}$ & $\mathrm{Cu}$ & $\mathrm{Cr}$ & $\mathrm{Zn}$ & $\mathrm{Mn}$ & $\mathrm{Ti}$ & $\mathrm{Al}$ \\
\hline $0.8-1.2$ & $0.4-0.8$ & $0.15-0.4$ & $0.04-0.35$ & $0.0-0.25$ & $0.0-0.15$ & $0.0-0.15$ & Balance \\
\hline
\end{tabular}


2. Number of levels for each factor: The number of levels considered for each factor is also 3.

3. Response values of the experiment: The response values considered are micro-hardness, tensile strength and grain size.

Three main effects are considered as follows.

1. Strain rate of specimen compression in $\mathrm{mm} / \mathrm{min}(\mathrm{A})$

2. Number of passes assigned for compression (B)

3. Thickness of the test specimen in $\mathrm{mm}(\mathrm{C})$

Three interaction effects are considered as follows.

1. Strain rate and number of passes ( $A B$ and $A C)$

2. Strain rate and Thickness (BA and $B C$ )

3. Number of passes and thickness ( $C A$ and $C B$ )

\subsection{Linear graph and interaction assignment}

Linear graph represents the interactions graphically and makes it easy to assign with factors and interactions to the various columns of an orthogonal array. In a linear graph, the columns of an orthogonal array are represented by dots and lines. The interaction of the two columns represented by the dots is confounded with the column represented by the line. In a linear graph, each column and each line has a distinct column numbers associated with it. Further, every column of the array is represented in its linear graph once only. In the present experiment the linear graph is constructed as shown in Fig. 1

Taguchi orthogonal array designs are repeatedly used in design of experiments with multiple level factors. The notation for matrix experiments $\mathrm{L}_{27}\left(3^{13}\right)$ shows the calculations for total number of experiments to be conducted which is 27 in this case and the number of factors being represented by $3^{13}$.

A total of 27 experiments were designed using Taguchi orthogonal array. The experiment's log, where different factors and their levels used in each experiment are as shown in Table 3.

The experimental conditions for the 27 experiments are as presented in Table 4. A total of 27 experiments were designed using Taguchi orthogonal array. Taguchi orthogonal array designs are repeatedly used in design of experiments with multiple level factors.

After setting the experimental parameters for each experiment, the responses are characterized as grain size, micro-hardness and tensile strength. The responses obtained according to each experiment conducted are shown in Table 5.

\section{Results and discussions}

\subsection{Grey relational analysis}

Grey relational analysis is widely used for measuring the degree of relationship between sequences by grey relational grade. Grey relational analysis has been applied by several researchers $[17,18]$ to optimize the control parameters having multi-responses through grey relational grade. The Grey relational analysis is widely used to combine all the considered performance characteristics into a single value that can be used as the single characteristic in optimization problems.
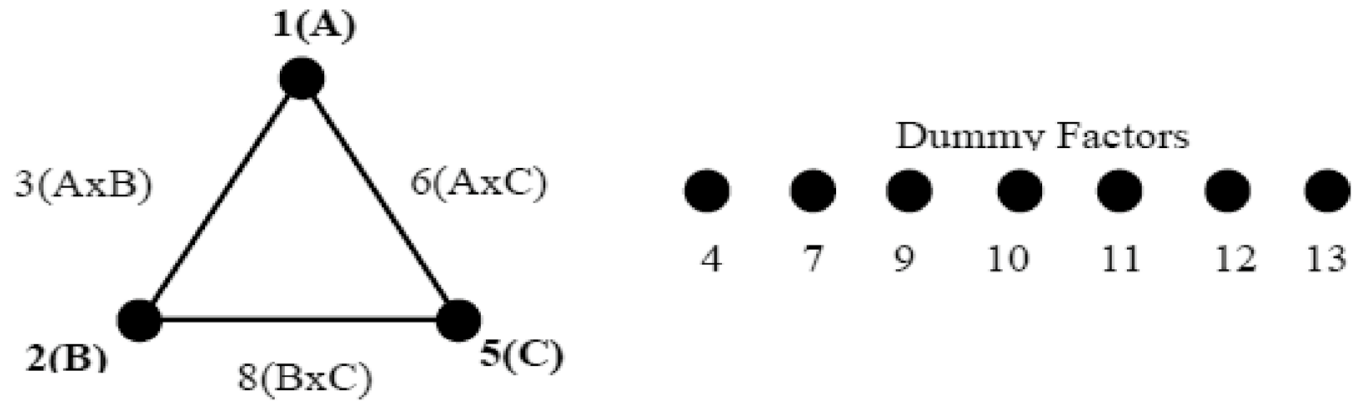

Experimental parameters and their levels

Main Effect

1(A) Displacement rate

2(B) number of passes

5(C) thickness
Interaction Effect

$3(\mathrm{AxB})$

$6(\mathrm{AxC})$

$8(\mathrm{BxC})$
Dummy factors

$4,7,9,10,11,12$ and 13

Fig. 1 Linear graph 
Table 3 Experiment's log, where different factors and their levels used in each experiment are shown

\begin{tabular}{|c|c|c|c|c|c|c|c|c|c|c|c|c|c|}
\hline \multirow[t]{3}{*}{ Expt. no. } & \multicolumn{6}{|c|}{$\begin{array}{l}\text { Column number and factor assign- } \\
\text { ment }\end{array}$} & \multirow[t]{3}{*}{ Expt. no. } & \multicolumn{6}{|c|}{ Column number and factor assignment } \\
\hline & 1 & 2 & 3 & 5 & 6 & 8 & & 1 & 2 & 3 & 5 & 6 & 8 \\
\hline & A & B & $A B$ & C & $A C$ & $B C$ & & A & B & $A B$ & $\mathrm{C}$ & $A C$ & $\mathrm{BC}$ \\
\hline 1 & 1 & 1 & 1 & 1 & 1 & 1 & 15 & 2 & 2 & 3 & 3 & 1 & 1 \\
\hline 2 & 1 & 1 & 1 & 2 & 2 & 2 & 16 & 2 & 3 & 1 & 1 & 2 & 3 \\
\hline 3 & 1 & 1 & 1 & 3 & 3 & 3 & 17 & 2 & 3 & 1 & 2 & 3 & 1 \\
\hline 4 & 1 & 2 & 2 & 1 & 1 & 2 & 18 & 2 & 3 & 1 & 3 & 1 & 2 \\
\hline 5 & 1 & 2 & 2 & 2 & 2 & 3 & 19 & 3 & 1 & 3 & 1 & 3 & 1 \\
\hline 6 & 1 & 2 & 2 & 3 & 3 & 1 & 20 & 3 & 1 & 3 & 2 & 1 & 2 \\
\hline 7 & 1 & 3 & 3 & 1 & 1 & 3 & 21 & 3 & 1 & 3 & 3 & 2 & 3 \\
\hline 8 & 1 & 3 & 3 & 2 & 2 & 1 & 22 & 3 & 2 & 1 & 1 & 3 & 2 \\
\hline 9 & 1 & 3 & 3 & 3 & 3 & 2 & 23 & 3 & 2 & 1 & 2 & 1 & 3 \\
\hline 10 & 2 & 1 & 2 & 1 & 2 & 1 & 24 & 3 & 2 & 1 & 3 & 2 & 1 \\
\hline 11 & 2 & 1 & 2 & 2 & 3 & 2 & 25 & 3 & 3 & 2 & 1 & 3 & 3 \\
\hline 12 & 2 & 1 & 2 & 3 & 1 & 3 & 26 & 3 & 3 & 2 & 2 & 1 & 1 \\
\hline 13 & 2 & 2 & 3 & 1 & 2 & 2 & 27 & 3 & 3 & 2 & 3 & 2 & 2 \\
\hline 14 & 2 & 3 & 2 & 2 & 3 & 3 & & & & & & & \\
\hline
\end{tabular}

Table 4 Experiment's log, where different factors and their levels used in each experiment

\begin{tabular}{|c|c|c|c|c|c|c|c|}
\hline \multirow[t]{2}{*}{ Expt. no. } & \multicolumn{3}{|c|}{ Experimental condition } & \multirow[t]{2}{*}{ Expt. no. } & \multicolumn{3}{|c|}{ Experimental condition } \\
\hline & $\begin{array}{l}\text { Displacement } \\
\text { rate }(\mathrm{mm} / \mathrm{min})\end{array}$ & No. of passes & $\begin{array}{l}\text { Thick- } \\
\text { ness } \\
(\mathrm{mm})\end{array}$ & & $\begin{array}{l}\text { Displacement } \\
\text { rate }(\mathrm{mm} / \mathrm{min})\end{array}$ & No. of passes & $\begin{array}{l}\text { Thick- } \\
\text { ness } \\
(\mathrm{mm})\end{array}$ \\
\hline 1 & 1 & 1 & 3 & 15 & 1.5 & 3 & 5 \\
\hline 2 & 1 & 1 & 4 & 16 & 1.5 & 5 & 3 \\
\hline 3 & 1 & 1 & 5 & 17 & 1.5 & 5 & 4 \\
\hline 4 & 1 & 3 & 3 & 18 & 1.5 & 5 & 5 \\
\hline 5 & 1 & 3 & 4 & 19 & 2 & 1 & 3 \\
\hline 6 & 1 & 3 & 5 & 20 & 2 & 1 & 4 \\
\hline 7 & 1 & 5 & 3 & 21 & 2 & 1 & 5 \\
\hline 8 & 1 & 5 & 4 & 22 & 2 & 3 & 3 \\
\hline 9 & 1 & 5 & 5 & 23 & 2 & 3 & 4 \\
\hline 10 & 1.5 & 1 & 3 & 24 & 2 & 3 & 5 \\
\hline 11 & 1.5 & 1 & 4 & 25 & 2 & 5 & 3 \\
\hline 12 & 1.5 & 1 & 5 & 26 & 2 & 5 & 4 \\
\hline 13 & 1.5 & 3 & 3 & 27 & 2 & 5 & 5 \\
\hline 14 & 1.5 & 3 & 4 & & & & \\
\hline
\end{tabular}

\subsection{Normalization of response values}

Normalization of response values are divided into three types according to expected nature of the response values. The first normalization is 'the smaller the better' values where the lowest values of the objective function are expected. Second is 'nominal the better' where the objective function has average values. The third one is 'higher the better' where highest values of the results are expected.
In the present study, the values for micro-hardness and tensile strength should increase with the grain refinement. Hence, 'higher the better' normalization criteria is considered for micro-hardness and tensile strength. The formula for 'higher the better' normalization criteria considered is as follows:

$x_{i}(k)=\frac{y_{i}(k)-\min y_{i}(k)}{\max y_{i}(k)-\min y_{i}(k)}$ 
Table 5 Data summary by experiments

\begin{tabular}{|c|c|c|c|c|c|c|}
\hline \multirow[t]{2}{*}{ Expt. no. } & \multicolumn{3}{|c|}{ Experimental condition matrix } & \multirow{2}{*}{$\begin{array}{l}\text { Micro hard- } \\
\text { ness (HV) }\end{array}$} & \multirow{2}{*}{$\begin{array}{l}\text { Tensile } \\
\text { strength } \\
(\mathrm{MPa})\end{array}$} & \multirow[t]{2}{*}{ Grain size $(\mu \mathrm{m})$} \\
\hline & $\begin{array}{l}\text { Displacement } \\
\text { rate }(\mathrm{mm} / \mathrm{min})\end{array}$ & No. of passes & $\begin{array}{l}\text { Thickness } \\
(\mathrm{mm})\end{array}$ & & & \\
\hline 01 & 1 & 1 & 3 & 44.48 & 94.82 & 7.7 \\
\hline 02 & 1 & 1 & 4 & 43.27 & 97.31 & 7.9 \\
\hline 03 & 1 & 1 & 5 & 43.02 & 76.38 & 8.0 \\
\hline 04 & 1 & 3 & 3 & 46.17 & 105.96 & 6.5 \\
\hline 05 & 1 & 3 & 4 & 45.50 & 109.81 & 6.4 \\
\hline 06 & 1 & 3 & 5 & 45.70 & 89.29 & 5.6 \\
\hline 07 & 1 & 5 & 3 & 49.20 & 113.00 & 3.8 \\
\hline 08 & 1 & 5 & 4 & 48.65 & 120.00 & 3.1 \\
\hline 09 & 1 & 5 & 5 & 47.98 & 96.00 & 4.0 \\
\hline 10 & 1.5 & 1 & 3 & 46.01 & 97.70 & 8.0 \\
\hline 11 & 1.5 & 1 & 4 & 44.38 & 96.92 & 7.2 \\
\hline 12 & 1.5 & 1 & 5 & 42.79 & 79.07 & 6.7 \\
\hline 13 & 1.5 & 3 & 3 & 47.62 & 104.95 & 6.7 \\
\hline 14 & 1.5 & 3 & 4 & 46.19 & 109.58 & 5.8 \\
\hline 15 & 1.5 & 3 & 5 & 45.45 & 91.10 & 5.0 \\
\hline 16 & 1.5 & 5 & 3 & 52.78 & 114.7 & 4.2 \\
\hline 17 & 1.5 & 5 & 4 & 52.73 & 119.01 & 3.5 \\
\hline 18 & 1.5 & 5 & 5 & 50.08 & 96.25 & 4.7 \\
\hline 19 & 2 & 1 & 3 & 46.33 & 95.92 & 8.0 \\
\hline 20 & 2 & 1 & 4 & 44.82 & 96.09 & 7.6 \\
\hline 21 & 2 & 1 & 5 & 42.33 & 78.69 & 6.4 \\
\hline 22 & 2 & 3 & 3 & 47.91 & 104.51 & 6.3 \\
\hline 23 & 2 & 3 & 4 & 46.02 & 112.10 & 5.6 \\
\hline 24 & 2 & 3 & 5 & 44.18 & 88.44 & 5.1 \\
\hline 25 & 2 & 5 & 3 & 52.13 & 115.13 & 4.2 \\
\hline 26 & 2 & 5 & 4 & 52.23 & 121.94 & 3.8 \\
\hline 27 & 2 & 5 & 5 & 49.63 & 97.10 & 4.6 \\
\hline
\end{tabular}

where,

$\mathrm{x}_{\mathrm{i}}(\mathrm{k})=$ value after the grey relational generation min $y_{i}(k)=$ smallest value of $y_{i}(k)$ for the $k$ th response $\max y_{i}(k)=$ largest value of the $y_{i}(k)$ for the $k$ th response

In the present work, it is observed that as value of grain size is decreased, the micro-hardness and tensile strength increases. Hence, the normalization criteria considered for grain size is that lower value is the better value. The analytical formula for 'lower the better' criteria considered is as follows:

$x_{i}(k)=\frac{\max y_{i}(k)-y_{i}(k)}{\max y_{i}(k)-\min y_{i}(k)}$

where,

$\mathrm{x}_{\mathrm{i}}(\mathrm{k})=$ value after the grey relational generation min $y_{i}(k)=$ smallest value of $y_{i}(k)$ for the $k$ th response $\max y_{i}(k)=$ largest value of the $y_{i}(k)$ for the $k$ th response

Accordingly, the normalized values of the responses are calculated and presented in Table 6 below.

Specimen calculation for Normalized value of micro hardness

$x_{i}(k)=\frac{y_{i}(k)-\min y_{i}(k)}{\max y_{i}(k)-\min y_{i}(k)}$

Accordingly, the normalized values of the responses are calculated and presented in Table 6 below.

$\min y_{i}(k)=$ smallest value of $y_{i}(k)$ for the $k$ th response $=42.33$

$\max y_{i}(k)=$ largest value of the $y_{i}(k)$ for the $k$ th response $=52.78$

$$
x_{i}(k)=\frac{44.48-42.33}{52.78-42.33}=\mathbf{0 . 2 0 6}
$$

Specimen calculation for Normalized value of Tensile strength 
Table 6 Normalized values for the responses

\begin{tabular}{|c|c|c|c|c|c|c|}
\hline Expt. no. & $\begin{array}{l}\text { Micro hard- } \\
\text { ness (HV) }\end{array}$ & $\begin{array}{l}\text { Normal- } \\
\text { ized value }\end{array}$ & $\begin{array}{l}\text { Tensile } \\
\text { strength } \\
(\mathrm{MPa})\end{array}$ & $\begin{array}{l}\text { Normal- } \\
\text { ized value }\end{array}$ & Grain size $(\mu \mathrm{m})$ & Normalize value \\
\hline 1 & 44.48 & 0.206 & 94.82 & 0.405 & 7.7 & 0.061 \\
\hline 2 & 43.27 & 0.090 & 97.31 & 0.459 & 7.9 & 0.020 \\
\hline 3 & 43.02 & 0.066 & 76.38 & 0.000 & 8.0 & 0.000 \\
\hline 4 & 46.17 & 0.367 & 105.96 & 0.649 & 6.5 & 0.306 \\
\hline 5 & 45.50 & 0.303 & 109.81 & 0.734 & 6.4 & 0.327 \\
\hline 6 & 45.70 & 0.322 & 89.29 & 0.283 & 5.6 & 0.490 \\
\hline 7 & 49.20 & 0.657 & 113.00 & 0.804 & 3.8 & 0.857 \\
\hline 8 & 48.65 & 0.605 & 120.00 & 0.957 & 3.1 & 1.000 \\
\hline 9 & 47.98 & 0.541 & 96.00 & 0.431 & 4.0 & 0.816 \\
\hline 10 & 46.01 & 0.352 & 97.70 & 0.468 & 8.0 & 0.000 \\
\hline 11 & 44.38 & 0.196 & 96.92 & 0.451 & 7.2 & 0.163 \\
\hline 12 & 42.79 & 0.044 & 79.07 & 0.059 & 6.7 & 0.265 \\
\hline 13 & 47.62 & 0.506 & 104.95 & 0.627 & 6.7 & 0.265 \\
\hline 14 & 46.19 & 0.369 & 109.58 & 0.729 & 5.8 & 0.449 \\
\hline 15 & 45.45 & 0.299 & 91.10 & 0.323 & 5.0 & 0.612 \\
\hline 16 & 52.78 & 1.000 & 114.7 & 0.841 & 4.2 & 0.776 \\
\hline 17 & 52.73 & 0.995 & 119.01 & 0.936 & 3.5 & 0.918 \\
\hline 18 & 50.08 & 0.742 & 96.25 & 0.436 & 4.7 & 0.673 \\
\hline 19 & 46.33 & 0.383 & 95.92 & 0.429 & 8.0 & 0.000 \\
\hline 20 & 44.82 & 0.238 & 96.09 & 0.433 & 7.6 & 0.082 \\
\hline 21 & 42.33 & 0.000 & 78.69 & 0.051 & 6.4 & 0.327 \\
\hline 22 & 47.91 & 0.534 & 104.51 & 0.617 & 6.3 & 0.347 \\
\hline 23 & 46.02 & 0.353 & 112.10 & 0.784 & 5.6 & 0.490 \\
\hline 24 & 44.18 & 0.177 & 88.44 & 0.265 & 5.1 & 0.592 \\
\hline 25 & 52.13 & 0.938 & 115.13 & 0.851 & 4.2 & 0.776 \\
\hline 26 & 52.23 & 0.947 & 121.94 & 1.000 & 3.8 & 0.857 \\
\hline 27 & 49.63 & 0.699 & 97.10 & 0.455 & 4.6 & 0.694 \\
\hline
\end{tabular}

$x_{i}(k)=\frac{y_{i}(k)-\min y_{i}(k)}{\max y_{i}(k)-\min y_{i}(k)}$

Accordingly, the normalized values of the responses are calculated and presented in Table 6 below.

$\min y_{i}(k)=$ smallest value of $y_{i}(k)$ for the $k$ th response $=76.38$

$\max y_{i}(k)=$ largest value of the $y_{i}(k)$ for the $k$ th response $=121.94$

$$
x_{i}(k)=\frac{94.82-76.38}{121.94-76.38}=\mathbf{0 . 4 0 5}
$$

\section{Specimen calculation for Normalized value of Grain size}

$x_{i}(k)=\frac{\max y_{i}(k)-y_{i}(k)}{\max y_{i}(k)-\min y_{i}(k)}$

Accordingly, the normalized values of the responses are calculated and presented in Table 6 below. min $y_{i}(k)=$ smallest value of $y_{i}(k)$ for the kth response $=3.1$

$\max y_{i}(k)=$ largest value of the $y_{i}(k)$ for the kth response $=8.0$

$$
x_{i}(k)=\frac{8.0-7.7}{8.0-3.1}=\mathbf{0 . 0 6 1}
$$

\subsection{Determining grey relational grades}

The grey relational degree is used to measure the correlation between the measurement spaces factor and the target sequence after a grey relational generation of the discrete sequence.

The grey relation coefficient $\xi_{i}(k)$ can be calculated using the below given equation.

$\xi_{\mathrm{i}}(\mathrm{k})=\frac{\Delta_{\min }+\xi \Delta_{\min }}{\Delta_{0 \mathrm{i}}(\mathrm{k})+\xi \Delta_{\max }}$

where,

$$
\Delta_{0 \mathrm{i}}=\left\|\mathrm{x}_{0}(\mathrm{k})-\mathrm{x}_{\mathrm{i}}(\mathrm{k})\right\|
$$


$\Delta_{0 i}$ : difference of the absolute value between the target sequence $x_{0}(k)$ and the comparison sequence $x_{i}(k)$; $\xi=$ distinguishing coefficient in between 0 and 1 . $\mathrm{x}_{0}(\mathrm{k})=$ ideal sequence or the target sequence; $x_{i}(k)=$ given sequence or the comparison sequence; $\Delta_{\text {min }}=\forall \mathrm{j} \min \in \mathrm{i} \forall_{\mathrm{k}} \min \left\|\mathrm{x}_{0}(\mathrm{k})-\mathrm{x}_{\mathrm{j}}(\mathrm{k})\right\|=$ smallest value of $\Delta_{0 \mathrm{i}}$

$\Delta_{\text {min }}:$ The absolute value of the minimum difference of the comparison sequence and the target sequence.

$\Delta_{\max }=\forall \mathrm{j} \max \in \mathrm{i} \forall_{\mathrm{k}} \max \left\|\mathrm{x}_{0}(\mathrm{k})-\mathrm{x}_{\mathrm{j}}(\mathrm{k})\right\|=$ largest value of $\Delta_{0 \mathrm{i}}$

$\Delta_{\max }:$ The absolute value of the maximum difference of the comparison sequence and the target sequence.

The grey relational coefficient results for the experimental data are shown in Table 7.

After averaging the grey relational coefficients, the grey relational grade $\gamma_{i}$ can be calculated using the below given equation.

$\gamma_{\mathrm{i}}=\frac{1}{\mathrm{n}} \sum_{\mathrm{k}=1}^{\mathrm{n}} \xi_{\mathrm{i}}(\mathrm{k})$

where $\mathrm{n}=$ number of process responses.

The grey relation coefficient $\xi_{\mathrm{i}}(\mathrm{k})$ can be calculated using the below given equation.

$\xi_{\mathrm{i}}(\mathrm{k})=\frac{\Delta_{\text {min }}+\xi \Delta_{\max }}{\Delta_{0 \mathrm{i}}(\mathrm{k})+\xi \Delta_{\max }}$

where,
$\Delta_{0 \mathrm{i}}=\left\|\mathrm{x}_{0}(\mathrm{k})-\mathrm{x}_{\mathrm{i}}(\mathrm{k})\right\|=$ difference of the absolute value between $\mathrm{x}_{0}(\mathrm{k})$ and $\mathrm{x}_{\mathrm{i}}(\mathrm{k})$;

$\xi=$ distinguishing coefficient in between zero and one. $\Delta_{\min }=\forall \mathrm{j} \min \in \mathrm{i} \forall_{\mathrm{k}} \min \left\|\mathrm{x}_{0}(\mathrm{k})-\mathrm{x}_{\mathrm{j}}(\mathrm{k})\right\|=$ smallest value of $\Delta_{0 \mathrm{i}}$

$\Delta_{\max }=\forall \mathrm{j} \max \in \mathrm{i} \forall_{\mathrm{k}} \max \left\|\mathrm{x}_{0}(\mathrm{k})-\mathrm{x}_{1}(\mathrm{k})\right\|=$ largest value of $\Delta_{0 \mathrm{i}}$. The grey relational coefficient results for the experimental data are shown in the Table 6.

After averaging the grey relational coefficients, the grey relational grade $\gamma_{i}$ can be calculated using the below given equation.

$$
\begin{aligned}
& \gamma_{\mathrm{i}}=\frac{1}{\mathrm{n}} \sum_{\mathrm{k}=1}^{\mathrm{n}} \xi_{\mathrm{i}}(\mathrm{k}) \\
& \xi=0.1 \mathrm{x}_{0}(\mathrm{k})=1 \mathrm{x}_{\mathrm{j}}(\mathrm{k})=\mathrm{x}_{27}(\mathrm{k}) \\
& \Delta_{\min }=\left\|\mathrm{x}_{0}(\mathrm{k})-\mathrm{x}_{27}(\mathrm{k})\right\|=(1-0.699)=0.301 \\
& \Delta_{\max }\left\|\mathrm{x}_{0}(\mathrm{k})-\mathrm{x}_{1}(\mathrm{k})\right\|=(1-0.206)=0.794 \\
& \Delta_{0 \mathrm{i}}(\mathrm{k})=\left\|\mathrm{x}_{0}(\mathrm{k})-\mathrm{x}_{2}(\mathrm{k})\right\|=(1-0.090)=0.91
\end{aligned}
$$

$\xi_{\mathrm{i}}(\mathrm{k})=\frac{\Delta_{\min }+\xi \Delta_{\max }}{\Delta_{0 \mathrm{i}}(\mathrm{k})+\xi \Delta_{\max }}$

$\xi_{\mathrm{i}}(\mathrm{k})=\frac{0.301+0.1(0.794)}{0.91+0.1(0.794)}=\mathbf{0 . 3 8 6}$

$\xi_{i}(k)=0.386$ (specimen calculations of grey relational value for micro hardness) similarly $\xi_{i}(k)=0.457$ (specimen calculations of grey relational

\begin{tabular}{|c|c|c|c|c|c|c|c|}
\hline \multirow[t]{2}{*}{ Expt. no. } & \multicolumn{3}{|c|}{ Grey relational values } & \multirow[t]{2}{*}{ Expt. no. } & \multicolumn{3}{|c|}{ Grey relational values } \\
\hline & $\begin{array}{l}\text { Micro } \\
\text { hardness } \\
\text { (HV) }\end{array}$ & $\begin{array}{l}\text { Tensile } \\
\text { strength } \\
(\mathrm{MPa})\end{array}$ & Grain size $(\mu \mathrm{m})$ & & $\begin{array}{l}\text { Micro } \\
\text { hardness } \\
(\mathrm{HV})\end{array}$ & $\begin{array}{l}\text { Tensile } \\
\text { strength } \\
(\mathrm{MPa})\end{array}$ & Grain size $(\mu \mathrm{m})$ \\
\hline 1 & 0.386 & 0.457 & 0.348 & 15 & 0.416 & 0.425 & 0.563 \\
\hline 2 & 0.355 & 0.480 & 0.338 & 16 & 1.000 & 0.759 & 0.690 \\
\hline 3 & 0.349 & 0.333 & 0.333 & 17 & 0.991 & 0.886 & 0.860 \\
\hline 4 & 0.441 & 0.588 & 0.419 & 18 & 0.659 & 0.470 & 0.605 \\
\hline 5 & 0.418 & 0.653 & 0.426 & 19 & 0.448 & 0.467 & 0.333 \\
\hline 6 & 0.425 & 0.411 & 0.495 & 20 & 0.396 & 0.468 & 0.353 \\
\hline 7 & 0.593 & 0.718 & 0.778 & 21 & 0.333 & 0.345 & 0.426 \\
\hline 8 & 0.559 & 0.922 & 1.000 & 22 & 0.518 & 0.567 & 0.434 \\
\hline 9 & 0.521 & 0.468 & 0.731 & 23 & 0.436 & 0.698 & 0.495 \\
\hline 10 & 0.436 & 0.484 & 0.333 & 24 & 0.378 & 0.405 & 0.551 \\
\hline 11 & 0.383 & 0.477 & 0.374 & 25 & 0.889 & 0.770 & 0.690 \\
\hline 12 & 0.343 & 0.347 & 0.405 & 26 & 0.905 & 1.000 & 0.778 \\
\hline 13 & 0.503 & 0.573 & 0.405 & 27 & 0.624 & 0.478 & 0.620 \\
\hline 14 & 0.442 & 0.648 & 0.476 & & & & \\
\hline
\end{tabular}
value for Tensile strength)
Table 7 Grey relational coefficient of each performance characteristics 
$\xi_{\mathrm{i}}(\mathrm{k})=0.348$ (specimen calculations of grey relational value for Grain size)

The higher the value of grey relational grade considered, the stronger is the relational degree between the ideal sequence $x_{0}(k)$ and the given sequence $x_{i}(k)$. Earlier it has been mentioned that the ideal sequence $x_{0}(k)$ is the best process response in the experimental layout. Here, it may be concluded that the higher relational grade means that the corresponding parameter combination is closer to the optimal.

Grey relational grade is calculated from the Table 7 based on the higher grey relational grade upon which its order or rank will be fixed.

Specimen calculations

Grey relation Grade $=$ average of grey relational values

Grey relation Grade $=\frac{0.386+0.457+0.348}{3}=\mathbf{0 . 3 9 7}$

Grey relational grade was calculated using grey relational analysis and the rank was allotted according to the grey relational grades. The highest value of the grey relational was considered as first rank experiment and further ranking was sorted from larger to smaller. The experimental setup which yielded first rank response values will be considered as an ideal experimental setup to obtain superior values of response. Table 8 shows the grey relational values along with the rank or order.

Table 8 The experimental results for the grey relational grade and its rank

\begin{tabular}{llrllr}
\hline Expt. no. & $\begin{array}{l}\text { Grey rela- } \\
\text { tional grade }\end{array}$ & Rank & Expt. no. & $\begin{array}{l}\text { Grey rela- } \\
\text { tional grade }\end{array}$ & Rank \\
\hline 1 & 0.397 & 23 & 15 & 0.468 & 16 \\
2 & 0.391 & 24 & 16 & 0.816 & 4 \\
3 & 0.338 & 27 & 17 & 0.912 & 1 \\
4 & 0.483 & 15 & 18 & 0.578 & 7 \\
5 & 0.499 & 13 & 19 & 0.416 & 20 \\
6 & 0.444 & 18 & 20 & 0.406 & 22 \\
7 & 0.696 & 6 & 21 & 0.368 & 25 \\
8 & 0.827 & 3 & 22 & 0.506 & 12 \\
9 & 0.573 & 9 & 23 & 0.543 & 10 \\
10 & 0.418 & 19 & 24 & 0.445 & 17 \\
11 & 0.411 & 21 & 25 & 0.783 & 5 \\
12 & 0.365 & 26 & 26 & 0.894 & 2 \\
13 & 0.494 & 14 & 27 & 0.574 & 8 \\
14 & 0.522 & 11 & & & \\
\hline
\end{tabular}

\subsection{Grey relational analysis from Taguchi technique}

Using the Taguchi Orthogonal Array (OA) technique, the designed experimental layout yielded the following response values of grain size, micro-hardness and tensile strength which are presented in Table 8.

Experiment 17 has the highest value of grey relational grade and it was allotted as rank one. The factors setup for experiment number 17 has $1.5 \mathrm{~mm} / \mathrm{min}$ as its displacement rate, 5 being the numbers of pass and thickness of specimen was $4 \mathrm{~mm}$. Table 9 shows the response values obtained from the experiment number 17. As per Table 9 , gives highest values on all the responses i.e., for $4 \mathrm{~mm}$ thickness Al 6061 sheet compressed by $1.5 \mathrm{~mm} / \mathrm{min}$ displacement rate up to 5 passes gives the lowest grain size of $3.5 \mu \mathrm{m}$ with micro-hardness value of $52.73 \mathrm{HV}$ and tensile strength $119.01 \mathrm{~N} / \mathrm{mm}^{2}$.

\subsection{ANOVA analysis}

The ANOVA analysis has been performed to predict the statistical significance of the process parameters. It helps to determine the effect of individual input parameter on output parameters. The results of ANOVA presented for CCGP in Table 10 provided below indicate the percentage contribution $(P)$ of each factor on the total variation with their degree of influence on the results obtained. The Table 10 shows the influence of Displacement Rate $(A=12.1 \%)$, number of passes $(B=77.8 \%)$, and thickness of the plate $(C=0.9 \%)$. It is observed that the pooled error is $0.009 \%$. Based on the results presented in Table 10, the number of passes is found to be the most influencing process parameter, followed by Displacement Rate and plate thickness as shown in Fig. 2. Table 10 also shows the ranking of process parameters generated by the conduct of Taguchi method.

\subsection{Response features}

The Response features are as follows:

1. Grain size $(\mu \mathrm{m})$

2. Micro hardness (HV)

3. Tensile strength (MPa)

\section{Effect of number of passes on grain size}

After each pass of corrugation and straightening, a high density of dislocations in the grains is achieved. The obtained grain boundaries are wavy and ill defined. The dislocation density decreases with increasing number of passes and the high angle grain boundaries are generated after five passes. The grain size after 1, 3, and 5 passes are measured. After five pass of corrugation and straightening, 
Table 9 Taguchi OA layout and response values

\begin{tabular}{|c|c|c|c|c|c|c|}
\hline \multirow[t]{2}{*}{ Expt. no. } & \multicolumn{3}{|c|}{ Experimental condition } & \multicolumn{3}{|l|}{ Response } \\
\hline & $\begin{array}{l}\text { Displacement } \\
\text { rate }(\mathrm{mm} / \mathrm{min})\end{array}$ & No. of passes & $\begin{array}{l}\text { Thickness } \\
(\mathrm{mm})\end{array}$ & Grain size $(\mu \mathrm{m})$ & $\begin{array}{l}\text { Micro hard- } \\
\text { ness (HV) }\end{array}$ & $\begin{array}{l}\text { Tensile } \\
\text { strength } \\
\text { (MPa) }\end{array}$ \\
\hline 1 & 1 & 1 & 3 & 7.7 & 44.48 & 94.82 \\
\hline 2 & 1 & 1 & 4 & 7.9 & 43.27 & 97.31 \\
\hline 3 & 1 & 1 & 5 & 8.0 & 43.02 & 76.38 \\
\hline 4 & 1 & 3 & 3 & 6.5 & 46.17 & 105.96 \\
\hline 5 & 1 & 3 & 4 & 6.4 & 45.5 & 109.81 \\
\hline 6 & 1 & 3 & 5 & 5.6 & 45.7 & 89.29 \\
\hline 7 & 1 & 5 & 3 & 3.8 & 49.2 & 113.00 \\
\hline 8 & 1 & 5 & 4 & 3.1 & 48.65 & 120.00 \\
\hline 9 & 1 & 5 & 5 & 4.0 & 47.98 & 96.00 \\
\hline 10 & 1.5 & 1 & 3 & 8.0 & 46.01 & 97.70 \\
\hline 11 & 1.5 & 1 & 4 & 7.2 & 44.38 & 96.92 \\
\hline 12 & 1.5 & 1 & 5 & 6.7 & 42.79 & 79.07 \\
\hline 13 & 1.5 & 3 & 3 & 6.7 & 47.62 & 104.95 \\
\hline 14 & 1.5 & 3 & 4 & 5.8 & 46.19 & 109.58 \\
\hline 15 & 1.5 & 3 & 5 & 5.0 & 45.45 & 91.10 \\
\hline 16 & 1.5 & 5 & 3 & 4.2 & 52.78 & 114.70 \\
\hline 17 & 1.5 & 5 & 4 & 3.5 & 52.73 & 119.01 \\
\hline 18 & 1.5 & 5 & 5 & 4.7 & 50.08 & 96.25 \\
\hline 19 & 2 & 1 & 3 & 8.0 & 46.33 & 95.92 \\
\hline 20 & 2 & 1 & 4 & 7.6 & 44.82 & 96.09 \\
\hline 21 & 2 & 1 & 5 & 6.4 & 42.33 & 78.69 \\
\hline 22 & 2 & 3 & 3 & 6.3 & 47.91 & 104.51 \\
\hline 23 & 2 & 3 & 4 & 5.6 & 46.02 & 112.10 \\
\hline 24 & 2 & 3 & 5 & 5.1 & 44.18 & 88.44 \\
\hline 25 & 2 & 5 & 3 & 4.2 & 52.13 & 115.13 \\
\hline 26 & 2 & 5 & 4 & 3.8 & 52.23 & 121.94 \\
\hline 27 & 2 & 5 & 5 & 4.6 & 49.63 & 97.10 \\
\hline
\end{tabular}

Table 10 ANOVA for multiple performance characteristics

\begin{tabular}{llllllr}
\hline Source & $\begin{array}{l}\text { Degrees of } \\
\text { freedom }\end{array}$ & $\begin{array}{l}\text { Sum of squares } \\
(\mathrm{SS})\end{array}$ & $\begin{array}{l}\text { Mean squares vari- } \\
\text { ance }(\mathrm{MS})\end{array}$ & $\mathrm{F}_{\text {cal }}$ & $\mathrm{F}_{\text {tab }}$ & $\% \mathrm{P}$ \\
\hline $\mathrm{A}$ & 2 & 0.091 & 0.046 & 12.439 & 8.65 & 12.1 \\
$\mathrm{~B}$ & 2 & 0.584 & 0.292 & 79.693 & 8.65 & 77.8 \\
$\mathrm{C}$ & 2 & 0.007 & 0.004 & 0.999 & 8.65 & 0.9 \\
$\mathrm{~A} \times \mathrm{B}$ & 4 & 0.001 & 0.000 & 0.096 & 7.01 & 0.2 \\
$\mathrm{~A} \times \mathrm{C}$ & 4 & 0.000 & 0.000 & 0.029 & 7.01 & 0.12 \\
$\mathrm{~B} \times \mathrm{C}$ & 4 & 0.037 & 0.009 & 2.520 & 7.01 & 4.9 \\
Error & 8 & 0.029 & 0.004 & & & \\
Total & 26 & 0.750 & - & & & \\
\hline
\end{tabular}

a total of $58 \%$ to $69 \%$ was achieved in all the three different thickness test specimens. These changes in the grain sizes is due to the extension of pre-existing boundaries in proportion to the strain and also due to the formation of new high angle grain boundaries formed by grain sub division.

\section{Effect of number of passes on microhardness}

After every pass of CCGP, the hardness of the specimen shows increasing trend with an average increase in hardness of all the specimens. Hall-Petch equation can be used to obtain the strength of any material which is inversely proportional to its grain size. By decreasing the average 


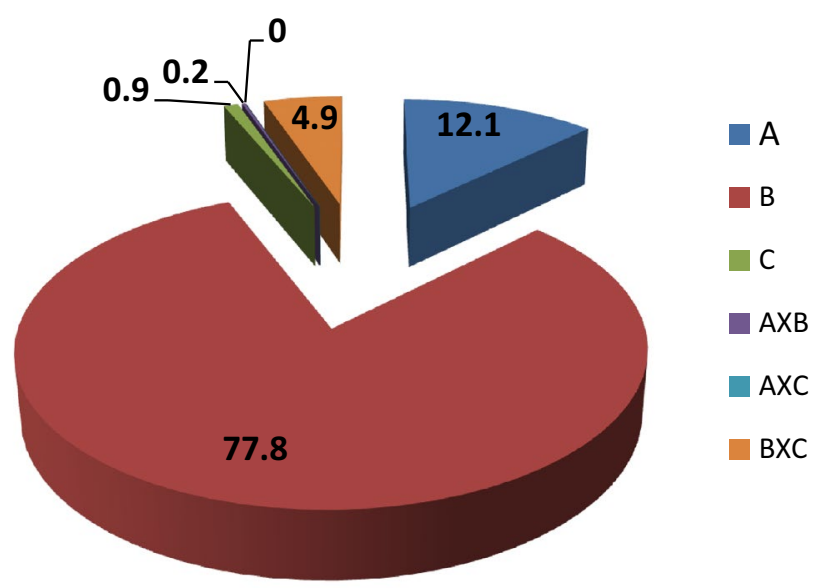

Fig. 2 Contribution of the most influencing parameters for physical properties of CCGP in percentage

grain size as in any SPD method, the yield strength of any material can be increased.

\section{Effect of number of passes on tensile strength}

The distribution of tensile strength values after each pass of the specimens was evaluated and the overall increase in tensile strength for all displacement rates was found to be $21 \%$ for $3 \mathrm{~mm}, 35 \%$ for $4 \mathrm{~mm}$ and $15 \%$ for $5 \mathrm{~mm}$. It can be concluded that on the basis of the results obtained, that the highest stress is observed for specimens with five passes of corrugation and straightening.

\section{Conclusions}

The objective of the research paper was to establish a relationship between pressing parameter like displacement rate, thickness of the plate and number of passes. The effect of these parameters on the microstructure and the mechanical properties of Al 6061 alloy were also studied in detail. It is important to develop an optimal severe plastic deformation process which has several utilities in practice. Due to the advantages of grey multiple attributes decision, it is clear that the number of passes (B) has the highest amount of contribution and the displacement rate $(A)$ has the second highest contribution on the response values. The thickness $(C)$ and interaction factors have a very less amount of contribution. The results in terms of the change in mechanical properties are discussed.

The Taguchi Orthogonal Array (OA) technique which was used to design the experimental layout yielded the response values of grain size, micro-hardness and tensile strength which are elaborately discussed. It was found that the experiment 17 has the highest value of grey relational grade and it was designated as rank one. The factors setup for experiment number 17 has $1.5 \mathrm{~mm} / \mathrm{min}$ as the displacement rate, 5 being the numbers of pass and thickness of specimen being $4 \mathrm{~mm}$.

In order to seek a proper manufacturing process which also meets the requirements of the industry, it is important to develop an accurate evaluation method. In the backdrop of the advantages of grey multiple attributes decision, this paper tries to propose an evaluation method to determine the overall performance for each of the factors considered.

\section{Compliance with ethical standards}

Conflict of interest On behalf of all authors, the corresponding author states that there is no conflict of interest.

\section{References}

1. Valiev Estrin Y, Horita Z, Langdon TG, Zechetbauer MJ, Zhu YT (2006) Producing bulk ultrafine-grained materials by severe plastic deformation. J Mater 58:33-39

2. Tsuji N, Saito Y, Lee SH, Minamino Y (2003) Accumulative rollbonding (ARB) and other new techniques to produce bulk ultrafine grained materials. Adv Eng Mater 5:338-344

3. Omotoyinbo JA, Oladele IO (2010) The effect of plastic deformation and magnesium content on the mechanical properties of 6063 aluminium alloys. J Miner Mater Charact Eng 9:539-546

4. Segal V (1995) Materials processing by simple shear. Mater Sci Eng 197:157-164

5. Cherukuri B, Srinivasan R (2006) Properties of AA6061 processed by multi-axial compressions/forging (MAC/F). Mater Manuf Processes 21:512-518

6. Shin DH, Park JJ, Kim YS, Park KT (2002) Constrained groove pressing and its application to grain refinement of aluminium. Mater Sci Eng A 328:98-103

7. Horita Z, Fujinami T, Langdon TG (2001) The potential for scaling ECAP: effect of sample size on grain refinement and mechanical properties. Mater Sci Eng A 318:34-41

8. Hayes JS, Keyte R, Prangnell PB (2000) Effect of grain size on the behavior of a submicron grained Al-3-wt\% Mg alloy produced by severe deformation. Mater Sci Technol 16:1259-1263

9. Baradeswaran A, Elayaperumal A, Issac FR (2013) A statistical

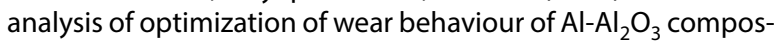
ites using Taguchi technique. Procedia Eng 64:973-982

10. Furukawa M, Iwahashi Y, Horita Z, Nemoto M, Langdon TG (1998) The shearing characteristics associated with equal-channel angular pressing. Mater Sci Eng A 257:328-332

11. Lowe TC, Valiev RZ (2004) The use of severe plastic deformation techniques in grain refinement. J Mater 56:64-68

12. Kurzydlowski KJ, Garbacz H, Richert M (2004) Effect of severe plastic deformation on the microstructure and mechanical properties of Al and Cu. Rev Adv Mater Sci 8:129-133

13. Radhika N, Subramaniam R (2013) Wear behaviour of aluminium/alumina/graphite hybrid metal matrix composites using Taguchi techniques. Ind Lubr Tribol 65:166-174

14. Girish BM, Satish BM, Sadananda Sarapure B (2016) Optimization of wear behaviour of magnesium alloy AZ91 hybrid 
composites using Taguchi experimental design. Metall Mater Trans 47A:3193-3200

15. Konda R, Rajurkar RR, Guha A, Parson M (1999) Design of experiments to study and optimise process performance. Int J Qual Reliab Manag 16:56-71

16. Dey A, Debanth S, Pandey KM (2017) Optimisation of electric discharge machining process parameters for AL 6061/cenosphere composites using grey based hybrid approaches. Trans Non-ferrous Met Soc China 27:998-1010

17. Kuo Yiyo, Tang Taho, Huang Guan-Wei (2008) The use of greybased Taguchi method for optimizing multi-response simulation problems. Eng Optim 40:517-528
18. Hunag JT, Liao YS (2003) Optimization of machining parameters of wire-EDM based on grey relational and statistical analyses. Int J Prod Res 41:1707-1720

Publisher's Note Springer Nature remains neutral with regard to jurisdictional claims in published maps and institutional affiliations. 